Clinica Chimica Acta

Flsevier Publishing Company, Amsterdam - Printed in The Netherlands

\title{
DEUTERIUM ISOTOPE EFFECTS IN THE METABOLISM OF $N$-ALKYLSUBSTITUTED AMPHETAMINES IN MAN
}

T. B. VREE, J. P. M. C. GORGELS, A. TH. J. M. MUSKENS AND J. M. VAN ROSSUM

Catholic University of Nijmegen, Department of Pharmacology, Geert Groote Plein N 21, Nijmegen (The Netherlands)

\section{SUMMARY}

Deuterium isotope effects in the metabolism of deuterated amphetamine and $N$-substituted deuterated amphetamines were studied in man. The isotope effect is large when in the elimination process of the amphetamine from the body, the metabolic processes, deamination and $N$-dealkylation are the major pathways and the renal excretion is the minor one. It appeared to be probable, that in the deamination and $\mathrm{N}$-dealkylation process the tertiary hydrogen atom is of importance.

\section{INTRODUCTION}

Within a series of $N$-alkyl substituted amphetamines it has been observed that the larger alkyl groups are more easily removed ( $N$-dealkylation) than the smaller groups; i.e. isopropyl $>$ ethyl > methyl. As a result of this dealkylation, amphetamine itself becomes the metabolite. Examination of the ratio of unaltered compound/ amphetamine metabolite, when the excretion is maximal, indicates a fixed ratio between the two substances. These ratios are: 6 for methylamphetamine, 2 for ethylamphetamine and 0.6 for isopropylamphetamine. Within the same series, we are dealing with the energy difference of the $\mathrm{C}-\mathrm{H}$ bond between the primary $\mathrm{H}$ of the methylgroup, secondary $\mathrm{H}$ of the ethylgroup and tertiary $\mathrm{H}$ of the isopropyl group. Whereas the dextro-isomers show the above decrease in ratio of compound/metabolite excreted, the levo-isomers show no change from one system to another, with all compounds exhibiting the same fixed ratio of $10: 1$. The physico-chemical parameters (e.g pKa, lipid solubility) of both isomers $(d+l)$ show only small differences, whereas the levo-isomer show no stimulant properties and are metabolized to a much lesser extent, indicating a sterical preference both for the stimulus receptor system and to the metabolizing enzyme system ${ }^{2,19}$.

Metabolic clearance of amphetamine derivatives involves three pathways: parahydroxylation, deamination and $N$-dealkylation. Dring ${ }^{8,7}$ has reported that, in man, the parahydroxylation is about $I-2 \%$ when the urinary excretion rate of the amphetamines is maximal. In view of the preceeding statement, itmay be assumed that the metabolic clearance due to parahydroxylation is negligible and that the overall elimination of amphetamines is due to excretion of unaltered compound, deamination 


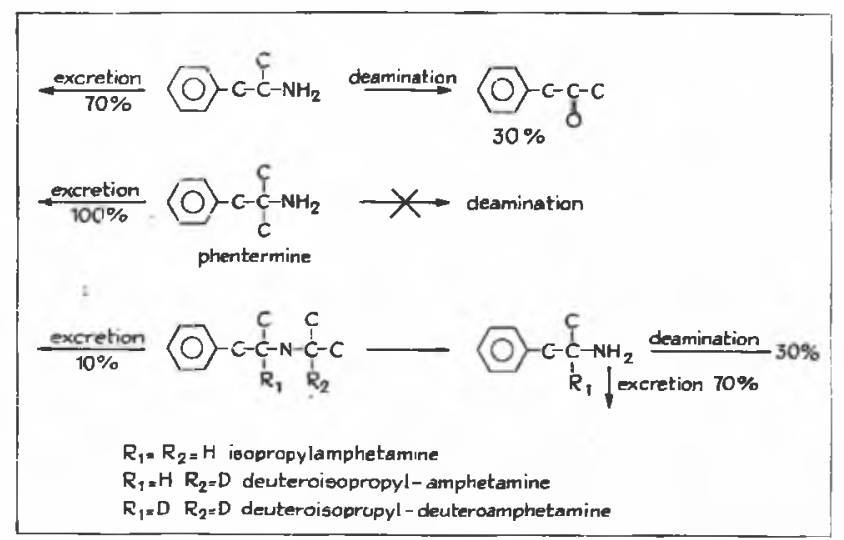

Fig. I. Elimination pathways of amphetamine, phentermine and the deuterated amphetamines.

and dealkylation. We may therefore assume that the sum of the unaltered amphetamine excreted, plus deaminated and dealkylated product is equivalent to $100 \%$ of the ingested dose.

In this manner, the percentage of deaminated amphetamine, found after excretion of $70 \%$ unaltered compound, is $30 \%$. (see Fig. I). Similar results are found when amphetamine and phentermine are compared. When these compounds are simultaneously administered to the same person, roo $\%$ of the phentermine and $70 \%$ of the amphetamine is excreted unaltered. The total amount of amphetamine excreted is dependent upon the ratio of metabolic and renal clearance constants, $\mathrm{km}$ resp. $\mathrm{kr}$ which in turn are dependent upon the physico-chemical parameters of both the amphetamine and the enzyme system ${ }^{12}$. Since from each amount of amphetamine absorbed or metabolically formed, $70 \%$ is excreted unaltered when amphetamine is a metabolite of some administered compound, the percentages of excretion, deamination and dealkylation of the original compound may be calculated ${ }^{12}$ (see Table I).

Phenylethylamine is excreted only $\mathbf{I}-5 \%$ unaltered. Comparison of this result to that of amphetamine plus its derivatives suggests that the deaminating enzyme is hindered when the aliphatic side chain is branched and/or that the deamination requires a hydrogen atom. If the deamination did not require the presence of a proton

TABLE I

\begin{tabular}{|c|c|c|c|c|}
\hline Compound & $\%$ Deamination & $\%$ Dealkylation & $\%$ Excretion* & $k_{r} \quad k_{m}$ \\
\hline + amphetamine & 30 & - & 70 & $\mathbf{k}_{\mathbf{r}}>\mathbf{k}_{\mathbf{m}}$ \\
\hline + methylamphetamine & 20 & 15 & 65 & $\mathbf{k}_{\mathbf{r}}>\mathbf{k}_{\mathbf{m}}$ \\
\hline + ethylamphetamine & 30 & 30 & 40 & $\mathbf{k}_{\mathbf{r}}=\mathbf{k}_{\mathbf{m}}$ \\
\hline + isopropylamphetamine & 45 & 45 & Io & $\mathbf{k}_{\mathbf{r}}<\mathbf{k}_{\mathbf{m}}$ \\
\hline + dimethylamphetamine & Io & 50 & 40 & $\mathbf{k}_{\mathbf{r}}=\mathrm{k}_{\mathrm{m}}$ \\
\hline - amphetamine : & Io & - & 90 & $\mathbf{k}_{\mathbf{r}}>\mathbf{k}_{\mathbf{m}}$ \\
\hline - methylamphetamine & IO & IO & 80 & $\mathbf{k}_{\mathbf{r}}>\mathbf{k}_{\mathbf{m}}$ \\
\hline - ethylamphetamine & o & ro & 90 & $\mathbf{k}_{\mathbf{r}}>\mathbf{k}_{\mathbf{m}}$ \\
\hline isopropylamphetamine & o & $\mathbf{I} 5$ & 85 & $\mathbf{k}_{\mathbf{r}}>\mathbf{k}_{\mathbf{m}}$ \\
\hline dimethylamphetamine & Io & 20 & 80 & $\mathbf{k}_{\mathbf{r}}>\mathbf{k}_{\mathbf{m}}$ \\
\hline
\end{tabular}

* \% of ingested dose, $\mathbf{k}_{\mathbf{r}}$ renal clearance constant, $\mathbf{k}_{\mathrm{m}}$ metabolic clearance constant. 
then we would have expected some deamination of the phentermine. Since the latter is excreted essentially unchanged, it may initially be assumed that the hydrogen atom is of importance. The purpose of this investigation therefore was to determine the importance of the alkyl hydrogen with respect to dealkylation and deamination and whether its abstraction was the rate limiting step.

When proton abstraction ( $\mathrm{C}-\mathrm{H}$ bond rupture) is believed to be the rate limiting step in the reaction sequence between a particular molecule and an enzyme system, the use of deuterium in place of hydrogen at the suspected position of proton abstraction may demonstrate the validity of the hypothesis; that is to say, if a deuterium isotope effect can be demonstrated, the corresponding $\mathrm{C}-\mathrm{H}$ bond exerts a determining role with respect to the rate limiting step ${ }^{1,4,10,11}$. In accordance with this, the hydrogen atom in question was replaced by a deuterium atom. The occurrence of a primary deuterium effect indicates a slower rate of $\mathrm{C}-\mathrm{D}$ bond rupture compared to $\mathrm{C}-\mathrm{H}$ bond rupture.

RESULTS

The resuits obtained give clear evidence as to the involvement of the tertiary hydrogen in both the $N$-dealkylating and deaminating sequence. It should be recogrized that, in the human body, several elimination mechanisms may mask a small deuterium effect.

The excretion rate, of the unaltered compound, which is maintained constant and maximal by maintaining the urine acidic, can be of importance. For example, when the hydrogen compound is excreted $50 \%$ unaltered and the deuterium compound is excreted $50.5 \%$ unaltered, the conclusions resulting from the cumulative excretion, may be that there is no isotope effect, whereas many observations may show a statistical significant effect. Other factors, such as the partition volume and the excretion rate of the deuterium and hydrogen compound may be different. The partition volumes and the excretion rates both depend upon the pKa value of the compound and this value may differ maximal 0.05 between the 2 compounds ${ }^{5}$ Table II. The deuterated compounds are more ionized than the hydrogen compounds at the $\mathrm{pH}$ of the blood $(7.40)$ Since the nonionized form of amphetamine is reabsorbed in the renal tubulus, the deuterated compounds are, or can be, more rapidly excreted than the hydrogen compounds. If the lather is true then the difference in excretion rate must be constant during the whole period of excretion and the deuterium content of the urine samples must gradually decrease.

TABLE II

\begin{tabular}{|c|c|}
\hline Drug & $p K a$ \\
\hline Amphetamine & $9.83 \pm 0.01$ \\
\hline Deuteroamphetamine & $9.88 \pm 0.01$ \\
\hline Methylamphetamine & $9.90 \pm 0.02$ \\
\hline Trideuteromethylamphetamine & $9.95 \pm 0.02$ \\
\hline Isopropylamphetamine & $10.31 \pm 0.01$ \\
\hline Deuteroisopropylamphetamine & $10.36 \pm 0.01$ \\
\hline Deuteroisopropyldeuteroamphetamine & $10.3^{8} \pm 0.01$ \\
\hline Dimethylamphetamine & $9.97 \pm 0.01$ \\
\hline Di-trideuteromethylamphetamine & $10.08 \pm 0.01$ \\
\hline
\end{tabular}


The retention time of the compounds on the Apiezon-KOH column reflects the lipid solubility of the compounds. The deuterium compounds tend to decrease the retention time and due to this observation it is unlikely that the lipid solubility and the related partition volume have increased.

When one is dealing with a deuterium effect in the metabolism, $(N$-deamination or the $N$-dealkylation), the enzymatic proces must be slower for the deuterium compound due to the higher force constant of the $\mathrm{C}-\mathrm{D}$ bond. Therefore, the gradual increase in the deuterium content to the hydrogen content in the urine at subsequent time intervals will be less, or even a decrease may be found.

In our study a continuous increase of the percentage deuterium in the samples was found indicating a necessary manifestation of the deuterium effect in the metabolism. The observation that the deuterated compound is excreted totally to a higher extent is secondary and is caused by factors other than the difference in metabolism. The increase of the percentage deuterium of the samples may be a large one, for instance with deuteroisopropylamphetamine or a small one, as with deuteroamphetamine.

\section{(+) deuterated amphetamine vs. (+) amphetamine (Table III) (Fig. 2).}

Observation of the deuterium percentage of amphetamine in the first urine sample after ingestion of both compounds $(50 \% \mathrm{H}, 50 \% \mathrm{D})$, and the deuterium content in one of the last urine samples $\left(48 \mathrm{~h}\right.$ ) indicates an appropiate increase of $I_{5} \%$ (Accuracy of the determination is $\pm 2 \%$.

TABRE III

DIFFERENCES IN EXCRETION AND METABOLISM OF DEUTEROAMPHETAMINE AND AMPHETAMINE $(+)$

\begin{tabular}{|c|c|c|c|c|c|c|c|c|c|}
\hline$\overline{\text { Subject }}$ & Dosis & $\% D$ dosis & $\% D$ start & $\% D$ end & $\% H$ excr. & $\% D$ excr. & $\%$ excr. & $\%$ & $p H$ \\
\hline J.G. : & I2 $\mathrm{mg}$ & 50.8 & 45 & 60 & 79 & 68.9 & IO.I & I5 & 5 \\
\hline F.H. & ro $\mathrm{mg}$ & 50.1 & 50 & 68 & 71.9 & 90 & I8.I & I 8 & 5 \\
\hline F.H. & $12 \mathrm{mg}$ & 50.4 & 53 & 62 & 70.7 & 88.4 & 17.7 & 9 & $5-6$ \\
\hline H.F. & $12 \mathrm{mg}$ & 50.0 & 54 & $6 \mathbf{I}$ & 54 & $75 \cdot 3$ & 20.3 & 7 & $5-7$ \\
\hline
\end{tabular}

From this data it can be concluded that there is a small deuterium effect. The composition of deuterium and hydrogen compound in the first urine samples determines the total cumulative excretion data. Foreman ${ }^{8}$ has shown with deuterated amphetamine a distinct deuterium effect with respect to metabolism by homogenized rabbit liver. The rabbit and human metabolize amphetamine in the same way, but from Table I it can be seen that when the renal excretion $\mathrm{kr}$ is more important than the metabolic clearance $\mathrm{km}$, the deuterium effect measured is small.

TABLE IV

DIFFERENCES IN METABOLISM AND EXCRETION BETWEEN $(+)$ METHYLAMPHETAMINE AND ( + ) TRIDEUTEROMETHYLAMPHETAMINE

\begin{tabular}{llllllllll}
\hline Subject & Dosis & $\% D$ dosis & $\% D$ start & $\% D$ end & $\% H$ excr. & $\% D$ excr. & $\%$ excr. & $\%$ & $p H$ \\
\hline W.V. & $7.7 \mathrm{mg}$ & $50 . I$ & 54 & 54 & 69 & 88 & 19 & 0 & 5 \\
L.S. & $7.0 \mathrm{mg}$ & 50.0 & 55 & 55 & 74 & 90 & 16 & 0 & 5 \\
J.G. & $7.5 \mathrm{mg}$ & 50.2 & 56 & 56 & $6 \mathbf{I . 3}$ & 75.7 & 14.4 & 0 & 5 \\
\hline
\end{tabular}

Clin. 'Chim. Acia, 34 (I97I) 333-344 


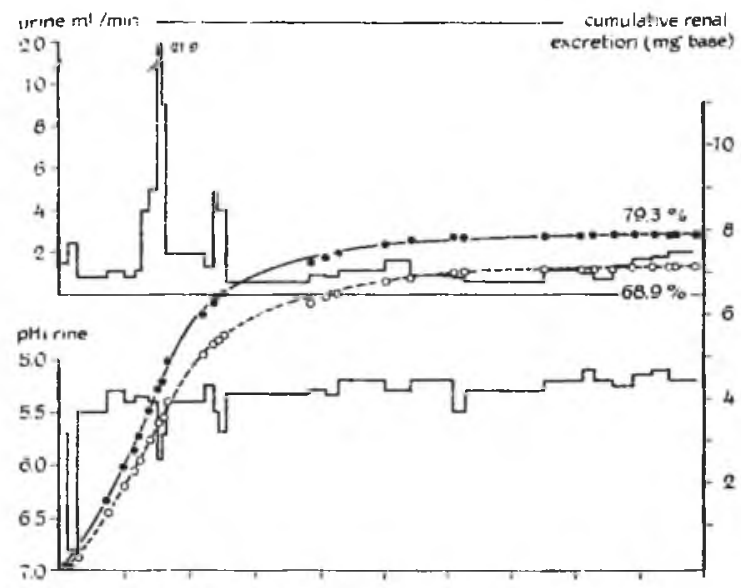

excretion rate ( $\mu \mathrm{g} / \mathrm{min} ; \log$ scale)

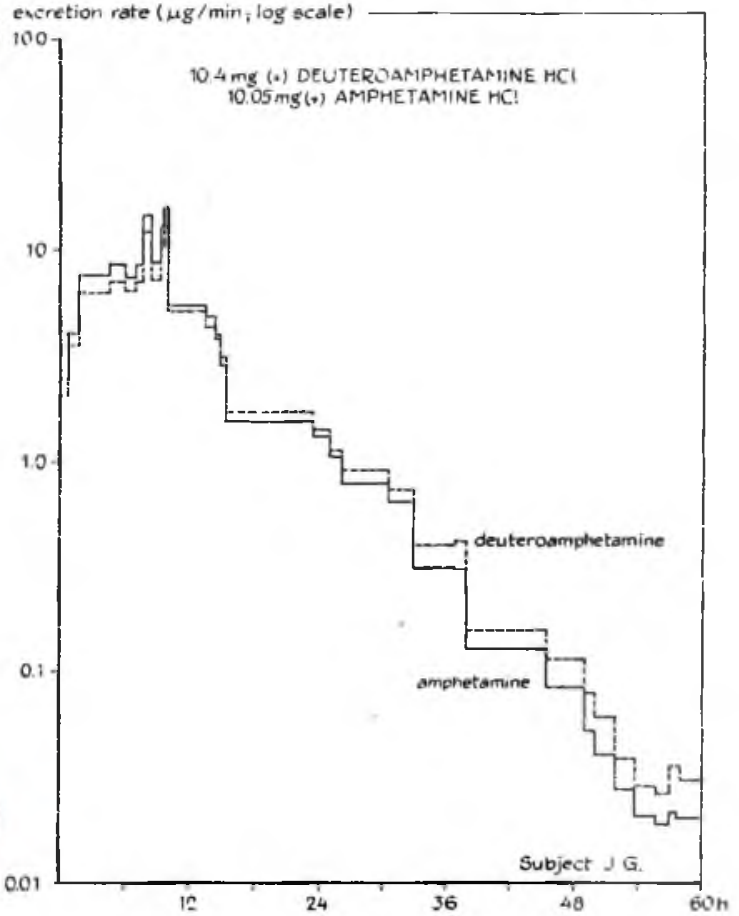

Fig. 2. Renal excretion rate, urine pH, urine production and cumulative excretion of dextroamphetamine and dextro-deuteroamphetamine. The deuterium content of the urine samples shifted from $50 \%$ in the first urine samples to $60 \%$ in the last ones (Table III). The difference in excretion rate between $\mathrm{D}$ - and $\mathrm{H}$-amphetamine is small, due to the fact that the renal clearance of the unaltered compound is much more important than the metabolic clearance (Table I).

\section{(+) trideuteromethylamphetamine vs. (+) methylamphetamine (Table IV)}

With methylamphetamine, the deuterium content of the urine samples varies between 52 and $56 \%$ throughout the total period and essentially there is no shift in the percentage deuterium. The total amount of trideuteromethylamphetamine excreted is higher than the amount of methylamphetamine excreted. 

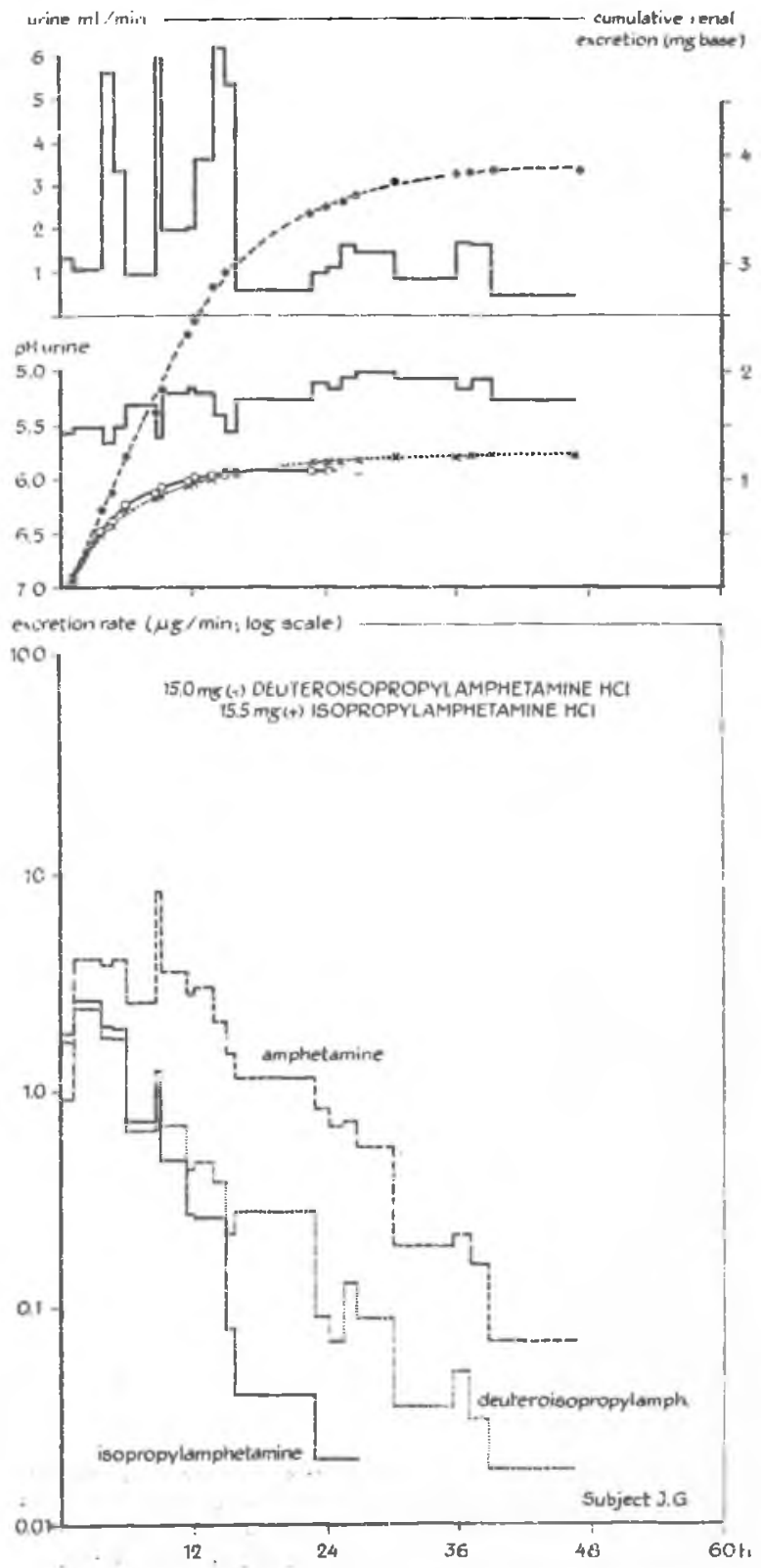

Fig. 3. Renal excretion rate, urine $\mathrm{pH}$, urine production and cumulative renal excretion of dextrodeuteroisopropylamphetamine and dextro-isopropylamphetamine. There is a remarkable deuterium effect, whichs, begins to $\mathbf{h}$ after ingestion of the compounds.

\section{$(+)$ di-trideuteromethylamphetamine vs. (+) dimethylamphetamine (Table V)}

... Dipnethylamphetamine does not show a deuterium effect in the $N$-dealkylation of the first and second methylgroup. The deuterium content of the urine samples varies but no deuterium shift is observed.

Clin. Chim. Acla, 34 (r971) 333-344 
TABL.E V

DIFFERENCES IN METhBOLISM AND EXCRETION BETWEEN $(+)$ DIMETHYLAMPHETAMINE AND $(+)$ DITRIDEUTEROMETHYLAMPHETAMINE

\begin{tabular}{|c|c|c|c|c|c|c|c|c|c|}
\hline Subject & Dosis & $\% D$ dosis & $\% D$ start & $\% D$ end & $\% / \mathrm{H}$ excr. & $\% D$ excr. & $\triangle \%$ excr. & $\Delta \%$ & $p H$ \\
\hline j.G. & $20 \mathrm{mg}$ & 50.1 & 50 & 60 & 18 & 27 & 9 & 10 & 5 \\
\hline J.B. & $2 \mathrm{I} \mathrm{mg}$ & 50.0 & 50 & $6 I$ & 18 & 24 & 6 & II & 5 \\
\hline J.H. & $14.6 \mathrm{mg}$ & 50.1 & 50 & 57 & 6 & 9 & 3 & 7 & 5 \\
\hline M.H. & $13.8 \mathrm{mg}$ & 50.2 & 59 & 60 & I 7 & 25 & 8 & I & 5 \\
\hline \multicolumn{10}{|c|}{ (-) dimethylamphetamine and (-) ditrideuteromethylamphetamine. } \\
\hline M.H. & I5 $\mathrm{mg}$ & 50.0 & 55 & 55 & 18 & 26 & 8 & O & 5 \\
\hline
\end{tabular}

The accuracy in \% $\mathrm{L}$ by means of massfragmentometry is $\pm 5 \%$.

\section{TABLE VI}

DIFFERENCES IN MOTABOLISM AND EXCRETION BETWEEN $(+)$ ISOPROPYLAMPHETAMINE AND $(+)$ DEUTEROISOPROPYLAMPHETAMINE

\begin{tabular}{|c|c|c|c|c|c|c|c|c|c|}
\hline jiect & Dosis & $\% D$ dosis & $\% D$ stayt & $\% D$ end & $\% H$ excr. & $\% D$ excr. & $\triangle \%$ excr. & $\triangle \%$ & $p H$ \\
\hline $\mathrm{T} . \mathrm{V}$. & $13 \mathrm{mg}$ & 50.0 & 48 & 90 & 13.7 & I 4.2 & 0.5 & 42 & 5 \\
\hline J.G. & $15 \mathrm{mg}$ & 49.5 & 48 & 89 & 8.35 & 9.90 & 1.55 & $4 I^{-}$ & 5 \\
\hline j.S. & I5. I mg & 49.5 & $4^{8}$ & 82 & 8.75 & IO.I 4 & I. 39 & 34 & 5 \\
\hline J.G. & $75 \mathrm{mg}$ & 50.0 & 48 & 90 & 5.0 & $6.5^{\circ}$ & 1.50 & 42 & 5 \\
\hline C.V. & I5 $\mathrm{mg}$ & 50,0 & $4^{8}$ & 80 & I. 2.1 & 12.4 & $0.3^{\circ}$ & 32 & 5 \\
\hline \multicolumn{10}{|c|}{$(-)$ isopropylamphetamine and $\{-\rangle$ deuteroisopropylamphetamine. } \\
\hline j.s. & I $5 \mathrm{mg}$ & 50.0 & $5 I$ & $5 I$ & 63.2 & 63.5 & 0.30 & o & 5 \\
\hline P.R. & $\mathrm{I} 6 \mathrm{mg}$ & 52.1 & 55 & 53 & $57 \cdot 3$ & 66.5 & 9.2 & o & 5 \\
\hline J.G. & I7 $\mathrm{mg}$ & 52.0 & 52 & 53 & 54.0 & 56.8 & 2.8 & 0 & 5 \\
\hline
\end{tabular}

\section{TABLE VIJ}

DIFFERENCES IN METABOUISM AND EXCRETION BETWEEN (+) ISOPROPYLAMPHETAMINE AND DEUTEROISOPROPYL-DEUTEROAMPHETAMINE

\begin{tabular}{|c|c|c|c|c|c|c|c|c|c|}
\hline Suojecs.s. & Dosis & $\% D$ dosis & $\% D$ start & $\% D$ end & $\% H$ excr. & $\% D$ excr. & $\triangle \%$ excr. & $\Delta \%$ & $p H$ \\
\hline C.V. & 44. I mg & 49.5 & 50 & 80 & 7.95 & 6.02 & I.93 & 30 & 5 \\
\hline T.V. & $43.0 \mathrm{mg}$ & 50.0 & 45 & 75 & 3.14 & 2.04 & I.IO & 30 & 5 \\
\hline J.B. & $42.3 \mathrm{mg}$ & $5 \mathrm{I} \cdot 3$ & 40 & 77 & $1.7^{\circ}$ & c.25 & 0.45 & 37 & 5 \\
\hline \multicolumn{10}{|c|}{$(-)$ isopropylamphetamine and $(-)$ deuteroisopropyldeuteroamphetamine. } \\
\hline F.H. & $41.6 \mathrm{mg}$ & 50.0 & 52 & 54 & 88 & 76 & I2 & 2 & 5 \\
\hline H.H. & $40.4 \mathrm{mg}$ & 50.1 & $5 I$ & $5^{2}$ & 82 & 80 & 2 & $I$ & 5 \\
\hline
\end{tabular}

$(+)$ deuteroisopropylamphetamine vs. $(+)$ isopropylamphetamine (Table VI) (Fig. 3) This compound elicits a rather large difference between the hydrogen and deuterium compound. The deuterium content increases from $48 \%$ to $90 \%$ in all the subjects, but in some subjects the deuterium shift begins or is measurable only ro $h$ after ingestion. When the urine is acidic, $(\mathrm{pH} 5)$ the total amount of isopropylamphetamine excreted in the first Io $h$ determined the total cumulative excretion and for this reason the differences between deuterium and hydrogen cumulative excretion are very small, in spite of the great deuterium shift. The dextro-isomer shows this effect, but the levo-isomer does not. From Table I it can be seen that for the dextro-isomer the metabolic processes of elimination are much more important than the renal excretion and that with levo-isopropylamphetamine the relationship between renal and metabolic clearance is reversed. 

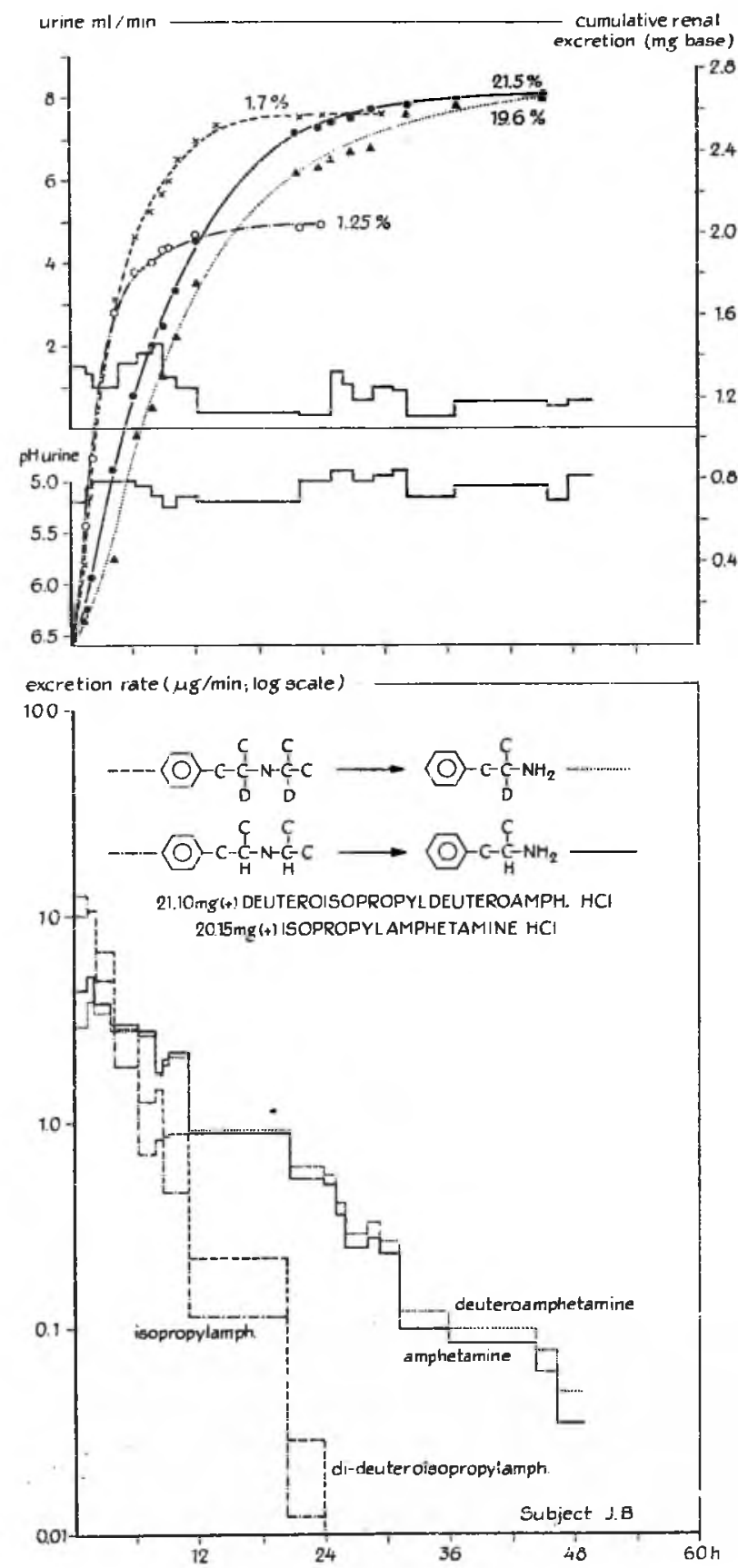

Fig. 4. Renal excretion rate, urine $\mathrm{pH}$, urine production and cumulative renal excretion of dextro deuteroiscpropyldeuteroamphetamine and dextroisoprcpylamphetamine. There is a deuteriumeffect of the same magnitude as mentioned in Fig. 3. 
(+) deuteroisopropyl-deuteroamphetamine vs. isopropylamphetamine(Table VII) (Fig. 4)

According to the results with deuteroisopropylamphetamine it was expected that the halflife time of deuteroisopropyldeuteroamphetamine would be doubled. The experiments, on the contrary, do not show a further increase in $\mathrm{T} I / 2$ of the dideuteroisopropylamphetamine. The reason for this may possibly be the following:

The purpose of the experiments was to prove that both tertiary hydrogen atoms in isopropylamphetamine are chemically identical for the enzyme. Therefore they were replaced by deuterium atoms in order to show that the hydrogen atoms in question are involved and are rate limiting. We have compared $\mathrm{H}$-isopropyl-with $\mathrm{D}$ isopropylamphetamine and found an increase in $\mathrm{T} \mathrm{I} / 2$ from $2 \mathrm{~h}$ to $4 \mathrm{~h}$ for the deuterium compound. From above experiments 2 hypotheses may follow:

Hypothesis $I$. The enzymes deaminate and dealkylate the $\mathbf{H}$ - and $\mathrm{D}$-isopropylamphetamine with the same affinity, thus, the difference in excretion rate and $\mathrm{T} I / 2$ is caused by the $\mathrm{C}-\mathrm{D}$ bond rupture.

Hypothesis $I I$. The enzyme can perform one metabolic action with the compound and after that action the compound leaves the enzyme action site.

If both dealkylation and deamination occurred at the same time, no amphetamine would be found as metabolite. When two different enzymes are involved, then the dideuterated isopropylamphetamine must be metabolized at a slower rate than the monodeuterated isopropylamphetamine. When we are comparing isopropyl: amphetamine with the dideuteroisopropylamphetamine and take into account hypothesis II, then it does not matter whether the C-D bond of the amphetamine moiety is broken or the $\mathrm{C}-\mathrm{D}$ bond of the isopropyl moiety is broken. When the isopropyl group has been removed, the metabolite shows the normal deuterium effect.

\section{EXPERIMENTS}

\section{Synthesis}

Deuterated dextro- and levo-amphetamine were synthesized according to Foreman $^{8}$. The rotations of the $d$ - and $l$-deuterated amphetamine found were: $(\alpha)_{\mathrm{D}}^{25}=+29.0^{\circ} \mathrm{C}=\mathrm{I} .995$ in water $(d$-tartrate salt $)$ and $(\alpha .)_{\mathrm{D}}^{25}=-28.0^{\circ} \mathrm{C} 2.005$ in water ( $l$-tartrate salt).

Di-trideuteromethylamphetamine. o.oI mole of $d$-amphetamine was treated with 0. I mole deuterated formic acid and 0.05 mole of trideuteroformaldehyde. The reaction was followed by means of gas chromatography-mass spectrometry. Completion of reaction was evidenced by disappearance of the basepeak at 72 ( $\mathrm{H}$-dimethylamphetamine) and the appearance of the base peak 78 (D-dimethylamphetamine). The levo isomer was prepared in a similar manner.

Trideuteromethylamphetamine. $500 \mathrm{mg}$ of the di-trideuteromethylamphetamine was oxidized by a tenfold excess of an alkaline permanganate solution and the reaction was followed by GLC-MS until the ditrideuteromethylamphetamine disappeared.

Deuteroisopropylamphetamine. $2 \mathrm{~g}$ of $d$-amphetamine were refluxed with $150 \mathrm{ml}$ of acetone and $5 \mathrm{~g}$ of anhydrous magnesium sulphate. The reaction was followed gaschromatographically. The acetone was removed by. vacuum and to the concentrated Schiff base $3 \mathrm{ml}$ of $\mathrm{D}_{2} \mathrm{O}$ and sufficient sodiumborodeuteride were added in small portions under reflux. The reduction was followed continuously by GLC-MSandstopped when the base peak of the Schiff base in thie mass spectrum $(m=84)$ had dissappeared. 
The mass spectrum of the deuteroisopropylamphetamine showed a base peak at $\mathrm{m}=87$. The levo isomer was prepared in the same way.

Deuteroisopropyl-deuteroamphetamine. I $\mathrm{g}$ of $d$-deuteroamphetamine is refluxed with ${ }^{5} 5 \mathrm{ml}$ of acetone and $5 \mathrm{~g}$ of ahydrous magnesiumsulphate. Due to the magnesiumsulphate the yield of the reaction is quantitative.

The excess of acetone is removed under vacuum and sodiumborodeuteride and $\mathrm{D}_{2} \mathrm{O}$ was added in small portions. The reduction was followed by GLC-mass spectrometry.

Full details of the reactions will be published elsewhere ${ }^{13}$.

METHODS

\section{Apparatus}

Gaschromatograph H P 402 with flame ionisation detection. Glass column, I.80 $\mathrm{m}, 3 \mathrm{~mm}$ diameter, filled with $20 \%$ Apiezon L 5\% KOH Diatoport-S-60-80 mesh. Oven temperature $160^{\circ}$, temperature injection block $200^{\circ}$ and temperature detector block $220^{\circ}$. Nitrogen flow $30 \mathrm{ml} / \mathrm{min}$, hydrogen flow $40 \mathrm{ml} / \mathrm{min}$ and air flow $300 \mathrm{ml} / \mathrm{min}$.

Gaschromatograph-massspectrometer LKB gooo.

Glass column I.20 m, $3 \mathrm{~mm}$ diameter, filled with $20 \%$ Apiezon L 5\% KOH Diatoport-S-60-80 mesh. Oven temperature $140^{\circ}$, injection block $200^{\circ}$ separator $220^{\circ}$ and ion source temperature $250^{\circ}$.

Ionisation energy $70 \mathrm{eV}$, trapcurrent $60 \mathrm{~mA}$, accelerating voltage $3.5 \mathrm{kV}$.

\section{Detection methods}

The concentration of the amphetamines in the urine of the subjects was measured by means of the gaschromatographic analysis with the internal standard method. The same samples were injected into the LKB gooo system in order to determine the percentage of deuterium of the sample.

\section{Determinations}

Mixtures of equal amounts of amphetamine and deuterated amphetamine were ingested as $\mathrm{HCl}$ salts by male subjects (Table III-VII).

The urine was kept acidic, $\mathrm{pH} 5.0 \pm 0.2$, by the ingestion of $\mathrm{r} .6 \mathrm{~g}$ of ammoniumchloride four times a day. Each amount of urine was collected for $60 \mathrm{~h}$ or until such time that the excretion rate was $\mathrm{I} \%$ of the maximum excretion rate. The $\mathrm{pH}$ of the urine sample was measured upon receipt with a Copenhagen Radiometer. The average urine production was measured and the curves of average renal excretion rate were constructed. To Io $\mathrm{ml}$ of the urine, Io $\mu \mathrm{g}$ of the internal standard $N$-methyl benzylamine was added and the solution made alkaline to $\mathrm{pH} \mathrm{I}_{3}$ with $\mathrm{KOH}$ pellets. Then the alkaline solution was extracted twice with Io $\mathrm{ml}$ of freshly distilled ether, the combined ether layers extracted with $5 \mathrm{ml} 2 \mathrm{~N} \mathrm{HCl}$. The acidic layer was made alkaline to $\mathrm{pH}$ I3 and extracted twice with Io $\mathrm{ml}$ of ether. The combined ether layers were evaporated under a mild stream of dry air until roo $\mu \mathrm{l}$ remained. 5-8 $\mu \mathrm{l}$ was injected into the gaschromatograph HP 402 and into the LKB 9000.

\section{Detection methods}

In order to be able to determine the ratio of deuterated-non deuterated amphet- 
amine in a mixture of these compounds, we used the mass spectrum of this mixture, taking the ratio of the base peaks as a measure for the ratio of concentrations in the mixture. A calibration curve was made using mixtures of $\mathrm{D}$ - and $\mathrm{H}$-amphetamines of known composition. The masses examined were: amphetamine-deuteroamphetamine, line intensities $\mathrm{m} / \mathrm{e}^{+} 44-45$ methylamphetamine-trideuteromethylamphetamine, line intensities $\mathrm{m} / \mathrm{e}^{+} 5^{8-6 \mathrm{I}}$ isopropylamphetamine-deuteroisopropylamphetamine, line intensities $\mathrm{m} / \mathrm{e}^{+} 86-87$ isopropylamphetamine-deuteroisopropyldeuteroamphetamine, line intensities $\mathrm{m} / \mathrm{e}^{+}$86-88 dimethylamphetamine-ditrideuteromethylamphetamine, mass fragmentometry ratio of peak areas of the masses 72 and 78 .

For the calibration curves, line intensities at various concentrations in the gaschromatographic peak were measured. The average ratio of the line intensities was used. This method is allowed when the retention times of the $\mathrm{H}$ - and $\mathrm{D}$-amphetamine are equal. When there is a difference in retention time, as is the case with dimethylamphetamine, the method of mass fragmentometry ${ }^{8}$ must be followed. For the other cornpounds both methods are followed but give the same calibration curve. The accuracy of the estimation of the percentage deuterium in the samples is $\pm 2 \%$.

An example of a calibration curve is given in Fig. 5 .

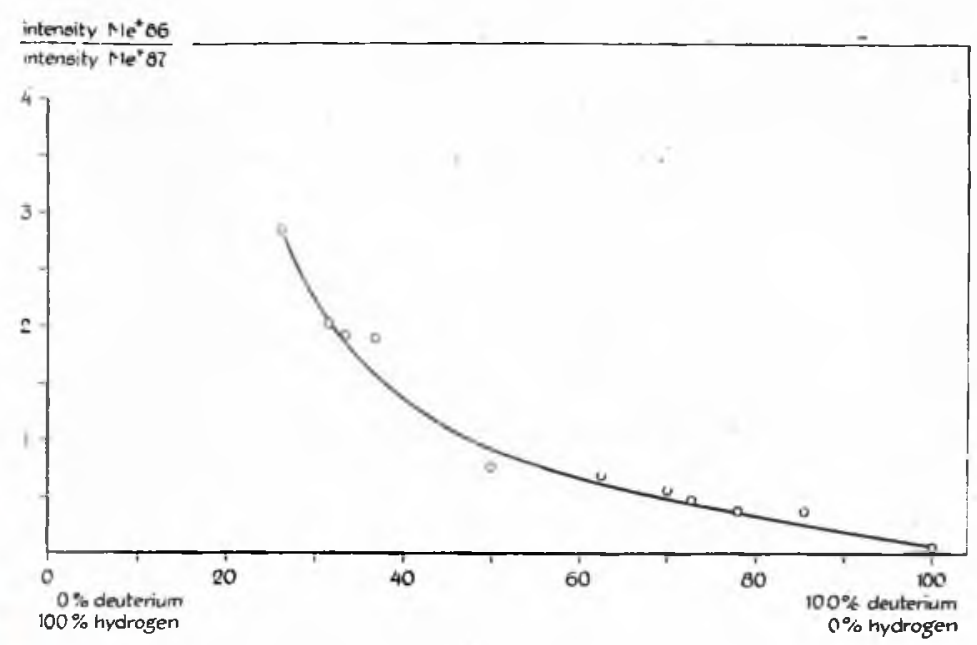

Fig. 5. Calibration curve of percentage deuteriumisopropylamphetamine and the ratio of line intensities of the base peaks $\mathrm{m} / \mathrm{e}^{+}=86$ and $\mathrm{m} / \mathrm{e}^{+}=87$.

Determination of $\mathrm{pKa}$ value of some amines by means of second differential titration curves

$\mathrm{pH}$ measurements were carried out with Radiometer equipment, consisting of a pH meter type PHM 26, equipped with a scale expander, a glass electrode type G 202 $B$ combined with a calomel electrode, type $\mathbf{K} 40 \mathrm{I}$. The system was calibrated using standard buffers: for iso-pH-adjustment: $0.025 \mathrm{M} \mathrm{KH}_{2} \mathrm{PO}_{4}(3.40225 \mathrm{~g} / \mathrm{I})$ and 0.025 $M \mathrm{Na}_{2} \mathrm{HPO}_{4} \cdot \mathrm{H}_{2} \mathrm{O}$ I2 (8.952 Io g/l) yieldings: $15^{\circ} \mathrm{pH} 6.900$

$20^{\circ} \mathrm{pH} 6.88 \mathrm{I}$

$25^{\circ} \mathrm{pH} 6.865$

Clin. Chim. Acta, 34 (197r) 333-344 
for electrode sensitivity adjustment: $0.05 \mathrm{M} \mathrm{KHphtalate} \mathrm{(I0.2II50} \mathrm{g/I)} \mathrm{with}$

$$
\begin{array}{r}
\mathrm{pH}=3.999 \text { at } 15^{\circ} \\
4.002 \text { at } 20^{\circ} \\
4.008 \text { at } 25^{\circ}
\end{array}
$$

The titration vessel was thermostated at $22^{\circ}$ and contained about $4 \mathrm{ml}$ solution. The titrant was carbonate free $\mathrm{KOH}$ o. Ioo $N$ (Titrisol, Merck). A microburette (max. volume $5 \mathrm{ml}$ ) was connected with a fine capillary, dipping into the solution. The plunger type burette had a accuracy of about $0.1 \%$ per $\mathrm{I} \mathrm{ml}$ titrant. The solution was stirred with a magnetic stirrer and kept under nitrogen. o.r mmole of the amine $\mathrm{HCl}$ salt was dissolved. The end point of the titration was determined by differentiating the $\mathrm{pH}$ curve and taking $\mathrm{d}^{2} \mathrm{pH} / \mathrm{dV}^{2}$ in which $\mathrm{V}$ is the added volume titrant. The $\mathrm{pKa}$ value was determined by interpolating in the $\mathrm{pH}$ curve.

\section{ACKNOWLEDGEMENTS}

The authors wish to thank Mr. P. J. van Gemert and Mr. J. Bormans for synthesizing the deuterated amphetamines, Mr. F. Bos for the measurement of the pKa values and Mr H. W. A. Hoeben and Dr. P. Doukas (Temple University, Philadelphia) for their critical remarks.

The authors wish to thank the various students who have taken and carefully excreted the deuterated compounds.

This study was supported by grants from the Netherlands Organization for Pure Scientific Research through its Fundamental Medical Research Organization.

\section{REFERENCES}

I H. AEBI, Kinetic isotope effects in metabolic studies with deuterated and tritiated compounds, International Conference on Radioactive Isotopes in Pharmacology. Wiley-Interscience, 1967, p. 305 .

2 A. H. Becketr, L. G. Brookes and E. V. B. Shenoy, Urinary excretion of the drug and its main metabolite in man, after the administration of $( \pm),(+)$ and $(-)$ ethylamphetamine, J. Pharm. Pharmacol., 21 (1969) I5I-S-156-S.

3 Ibid, Amphetamine and related compounds. Raven press New York (1970).

4 C. J. Collins, Some aspects of deuterium isotope effects in mechanism studies, Ann. New York Acad. Sci., 84 (1960) 603.

5 E. Elison, H. Rapoport, R. Laursen and H. W. Elliot, Effect of deuteration of $\mathrm{N}_{-} \mathrm{CH}_{3}$ group on potency and enzymatic N-demethylation of morphine, Science, I34 (1961) 1078.

6 L. G. Dring, R. L. Smith and R. T. Williams, The fate of amphetamine in man and other mammals, J. Pharm. Pharmacol., i 8 (1966) 402.

7 Ibid, Patterns of metabolism of $\alpha$-phenylisopropylamines in man and other species, Amphetamine and Related compounds, Raven Press, New York, I970, p. I21.

8 R. L. Foreman, F. P. Sítegel and R. G. Mrtek, Synthesis of deutero- $l$-amphetamine $d_{1}$ sulphate, J. Pharm. Sci., 58 (I969) 189.

9 B. Holmstedt, C. G. Hammar and R. RYhage, Identification of chlorpromazine and its metabolites in human blood by a new method, Anal. Biochem., 25 (I968) 532.

Io I. A. Rose, The use of kinetic isotope effects in the study of metabolic control, J. Biol. Chem., 236 (Ig6r) 603 .

I I V. J. Shiner, H. R. MahleR, R. H. Baker and R. R. Hiatt, Secondary deuterium isotope effects in chemical and biochemical reactions, Ann. New York Acad. Sci., 84 (1960) 583.

I2 T. B. VREe AND J. M. VAN Rossum, Kinetics of metabolism and excretion of amphetamines in man, Amphetamine and Related compounds. Proceedings of the Mario Negri Institute for Pharmacological Research, Milan, E. Costa And S. Garatini (Eds.), Raven Press, New York, I970, p. I 56.

I3 T. B. VREE, Thesis, University of Nijmegen, I97I.

Clin. Chim. Acta, 34 (1971) 333-344 